\title{
In-situ observations and modeling of small nitric acid-containing ice crystals
}

\author{
C. Voigt ${ }^{1}$, B. Kärcher ${ }^{1}$, H. Schlager ${ }^{1}$, C. Schiller ${ }^{2}$, M. Krämer ${ }^{2}$, M. de Reus ${ }^{3}$, H. Vössing ${ }^{3}$, S. Borrmann ${ }^{3,4}$, and \\ V. Mitev ${ }^{5}$ \\ ${ }^{1}$ Institut für Physik der Atmosphäre, DLR Oberpfaffenhofen, Germany \\ ${ }^{2}$ Institut für Chemie und Dynamik der Geosphäre, FZ Jülich, Jülich, Germany \\ ${ }^{3}$ Institut für Physik der Atmosphäre, Universität Mainz, Mainz, Germany \\ ${ }^{4}$ Max-Planck-Institut für Chemie, Abteilung Wolkenphysik, Mainz, Germany \\ ${ }^{5}$ Observatory of Neuchâtel, Neuchâtel, Switzerland
}

Received: 10 January 2007 - Published in Atmos. Chem. Phys. Discuss.: 5 February 2007

Revised: 4 May 2007 - Accepted: 31 May 2007 - Published: 27 June 2007

\begin{abstract}
Measurements in nascent ice forming regions are very rare and help understand cirrus cloud formation and the interactions of trace gases with ice crystals. A tenuous cirrus cloud has been probed with in-situ and remote sensing instruments onboard the high altitude research aircraft Geophysica M55 in the tropical upper troposphere. Besides microphysical and optical particle properties, water $\left(\mathrm{H}_{2} \mathrm{O}\right)$ and reactive nitrogen species $\left(\mathrm{NO}_{\mathrm{y}}\right)$ have been measured. In slightly ice supersaturated air between 14.2 and $14.9 \mathrm{~km}$ altitude, an unusually low ice water content of $0.031 \mathrm{mg} \mathrm{m}^{-3}$ and small ice crystals with mean radii of $5 \mu \mathrm{m}$ have been detected. A high nitric acid to water molar ratio $\left(\mathrm{HNO}_{3} / \mathrm{H}_{2} \mathrm{O}\right)$ of $5.4 \times 10^{-5}$ has been observed in the ice crystals, about an order of magnitude higher compared to previous observations in cirrus at temperatures near $202 \mathrm{~K}$. A model describing the trapping of $\mathrm{HNO}_{3}$ in growing ice particles shows that a high $\mathrm{HNO}_{3}$ content in ice crystals is expected during early growth stages, mainly originating from uptake in aerosol particles prior to freezing. Water vapor deposition on ice crystals and trapping of additional $\mathrm{HNO}_{3}$ reduces the molar ratio to values close to the ratio of $\mathrm{HNO}_{3} / \mathrm{H}_{2} \mathrm{O}$ in the gas phase while the cloud ages.
\end{abstract}

\section{Introduction}

Cirrus clouds in the upper troposphere affect the radiation budget of the Earth (Hartmann et al., 1992). In addition, cirrus clouds change the chemical composition of the upper troposphere through uptake of water $\left(\mathrm{H}_{2} \mathrm{O}\right)$ and nitric acid $\left(\mathrm{HNO}_{3}\right)$ (Meier and Hendricks, 2002), and het-

Correspondence to: C. Voigt

(christiane.voigt@dlr.de) erogeneous processing of hydroperoxy radicals and halogen species (Borrmann et al., 1996; Meilinger et al., 2001). Although a recent global model study concluded that the calculated overall effect of $\mathrm{HNO}_{3}$ uptake in cirrus clouds on upper tropospheric ozone concentrations could be small (von Kuhlmann and Lawrence, 2006), large uncertainties in factors controlling the distribution of trace gases and the chemistry of ozone in the tropopause region (Law et al., 2006) may render such a conclusion moot. It is therefore important to understand the microphysical details of the interaction between $\mathrm{HNO}_{3}$ and $\mathrm{H}_{2} \mathrm{O}$ vapor and cirrus ice crystals in order to properly assess the radiative properties of cirrus clouds, the effect of $\mathrm{HNO}_{3}$ and other trace gases on ice microphysics, and the role of cirrus in the chemistry of the global upper troposphere and lowermost stratosphere (Gao et al., 2004).

In the present study, we investigate a region of ice supersaturated, cold air in the subtropical upper troposphere with very low amounts of particulate water. Besides measurements of $\mathrm{H}_{2} \mathrm{O}$ and particles, reactive nitrogen species $\left(\mathrm{NO}_{\mathrm{y}}=\mathrm{HNO}_{3}+\mathrm{NO}+\mathrm{NO}_{2}+\mathrm{N}_{2} \mathrm{O}_{5}+\mathrm{PAN}+\ldots\right)$ have been detected in the gas and particle phase to study the interaction of $\mathrm{HNO}_{3}$ molecules with small ice particles. Previous measurements of $\mathrm{HNO}_{3}$ uptake in cirrus, compiled in Voigt et al. (2006), present data averaged over many different stages of cirrus cloud evolution. In this work, we present optical and microphysical measurements in an ice cloud that was - based on the available observational evidence - in its formation stage. The region has been crossed with the high altitude research aircraft Geophysics M55 on 17 February 2005 during the Tropical Convection, Cirrus and Nitrogen Oxide Experiment (TROCCINOX) while ascending from Araçatuba, Brazil $\left(19.7^{\circ} \mathrm{S}, 50.2^{\circ} \mathrm{W}\right)$, into the tropopause region near $17 \mathrm{~km}$ altitude.

Published by Copernicus Publications on behalf of the European Geosciences Union. 
We have measured unusually high $\mathrm{HNO}_{3} / \mathrm{H}_{2} \mathrm{O}$ molar ratios in the ice phase. We show that a high $\mathrm{HNO}_{3}$ content relative to $\mathrm{H}_{2} \mathrm{O}$ in ice is expected during initial stages of ice particle growth, evolving towards a lower $\mathrm{HNO}_{3}$ content in ice as the cloud particles age. To this end, we numerically simulate the $\mathrm{HNO}_{3} / \mathrm{H}_{2} \mathrm{O}$ ratio in freezing supercooled ternary solution (STS) aerosol at the time of ice nucleation and additional trapping of $\mathrm{HNO}_{3}$ during depositional growth of the nucleated ice particles (Kärcher and Basko, 2004). We have shown recently that a steady-state version of this approach unifies available observations of $\mathrm{HNO}_{3}$ uptake in cirrus clouds (Kärcher and Voigt, 2006). Our trapping model is also able to extrapolate the TROCCINOX data to aged cloud conditions, allowing us to compare them to previous data sets.

\section{Instrumentation}

Total $\mathrm{NO}_{\mathrm{y}, \mathrm{t}}$ (gas phase plus enhanced particle $\mathrm{NO}_{\mathrm{y}}$ ) as well as gas phase NO were measured on the Geophysica using the chemiluminescence technique (Fahey et al., 1985). Here we concentrate on measurements of $\mathrm{NO}_{\mathrm{y}, \mathrm{t}}$ through the forward facing inlet of the $\mathrm{NO}_{\mathrm{y}}$ instrument (Voigt et al., 2005). Ice crystals evaporate in the heated inlet $\left(35^{\circ} \mathrm{C}\right)$, the resulting gas phase $\mathrm{NO}_{\mathrm{y}}$ is catalytically reduced to $\mathrm{NO}$ with $\mathrm{CO}$ in a gold converter $\left(300^{\circ} \mathrm{C}\right)$, and finally the chemiluminescence reaction of $\mathrm{NO}$ with $\mathrm{O}_{3}$ is detected. Complete evaporation of ice crystals with radii $r_{i} \leq 10 \mu \mathrm{m}$ in the $\mathrm{NO}_{\mathrm{y}}$ instrument has been calculated for an inferred particle transition time of $\sim 0.1 \mathrm{~s}$ through the inlet and the converter. Submicrometersized particles evaporate even faster in the heated inlet, because they carry a much smaller amount of $\mathrm{H}_{2} \mathrm{O}$ at similar vapor pressures. In the following, $r$ denotes the particle radius (aerosol and/or ice crystals) and $r_{i}$ the ice crystal radius, if not directly stated otherwise.

If the particle velocity in the inlet is smaller than the aircraft velocity, the detected particle concentrations are enhanced relative to ambient values. For large particles $(r>5 \mu \mathrm{m})$, the enhancement factor $E$ is proportional to the ratio of aircraft velocity and sample flow velocity inside the inlet (Krämer and Afchine, 2004). The enhancement factor increases strongly in the size range $0.1 \mu \mathrm{m}<r<3 \mu \mathrm{m}$. We neglect the size dependence of $E_{i}$ for the supermicrometersized (ice) particles shown in Sect. 3.1, because the deviation of $E_{i}$ from its maximum value is $<8 \%$ when $r>3 \mu \mathrm{m}$. We account for changes in aircraft velocity and pressure, leading to $21.3<E_{i}<23.9$ in the cirrus region. For submicrometersized (aerosol) particles, we find $E_{a} \approx 4$ for an assumed radius of $0.25 \mu \mathrm{m}$ (Krämer and Afchine, 2004). This also means that the $\mathrm{NO}_{\mathrm{y}}$ instrument detects $\mathrm{HNO}_{3, \mathrm{i}}$ contained in ice more efficiently compared to $\mathrm{HNO}_{3, \mathrm{a}}$ contained in smaller aerosol particles.

We derive the nitric acid content in particles from measurements of total $\mathrm{NO}_{\mathrm{y}, \mathrm{t}}$ as $\mathrm{HNO}_{3, \mathrm{i}}=\left(\mathrm{NO}_{\mathrm{y}, \mathrm{t}}-\mathrm{NO}_{\mathrm{y}, \mathrm{r}}\right) / E_{i}$.
(Recall that NO has been measured in the second channel of the $\mathrm{NO}_{\mathrm{y}}$ instrument.) Gamblin et al. (2006) discuss potential non- $\mathrm{HNO}_{3}$ components of $\mathrm{NO}_{\mathrm{y}}$ condensing on ice crystals and suggest that $\mathrm{HNO}_{3}$ is often the major component of $\mathrm{NO}_{\mathrm{y}}$ in ice particles. Here, we assume that $100 \%$ of $\mathrm{NO}_{\mathrm{y}}$ in particles is $\mathrm{HNO}_{3}$.

In the above relationship, $\mathrm{NO}_{\mathrm{y}, \mathrm{r}}$ denotes the remaining $\mathrm{NO}_{\mathrm{y}, \mathrm{r}}=\mathrm{NO}_{\mathrm{y}, \mathrm{g}}+\mathrm{HNO}_{3, \mathrm{a}}$ in the cirrus region, and $\mathrm{HNO}_{3, \mathrm{a}}$ denotes the enhanced $\mathrm{HNO}_{3}$ contained in liquid aerosol, whereby $\mathrm{HNO}_{3, \mathrm{a}} \ll \mathrm{NO}_{\mathrm{y}, \mathrm{g}}$. We estimate $\mathrm{NO}_{\mathrm{y}, \mathrm{r}}$ from measurements above the cloud top and in a region free of particles with $r>1 \mu \mathrm{m}$ shown in Sect. 3, yielding similar values. Estimates of the $\mathrm{HNO}_{3}$ partitioning between the gas and the liquid aerosol phase are calculated in Sect. 3.2. We address the sensitivity of the results depending on different assumptions of $\mathrm{NO}_{\mathrm{y}, \mathrm{r}}$ in Sects. 3 and 4 . To extract an $\mathrm{HNO}_{3}$ concentration in the gas phase needed for model analysis, we assume that $50 \%$, within a likely range of $20-80 \%$, of $\mathrm{NO}_{\mathrm{y}, \mathrm{r}}$ was present in the form of $\mathrm{HNO}_{3}$. The detection limit for the volume mixing ratio of $\mathrm{HNO}_{3, \mathrm{i}}$ is 3 pmol mol${ }^{-1}$ (Voigt et al., 2006). The instrumental error of $\mathrm{NO}_{\mathrm{y}, \mathrm{t}}$ is $\pm 12 \%$.

Total (gas phase plus enhanced particulate) $\mathrm{H}_{2} \mathrm{O}_{t}$ was measured with the Lyman- $\alpha$ hygrometer FISH (Schiller et al., 1999) onboard the Geophysica. The accuracy of the FISH hygrometer is $8 \%$ in regions without particle observation.

We derive the ice water content (IWC) from measurements of total $\mathrm{H}_{2} \mathrm{O}_{\mathrm{t}}$ as $\mathrm{H}_{2} \mathrm{O}_{\mathrm{i}}=\left(\mathrm{H}_{2} \mathrm{O}_{\mathrm{t}}-\mathrm{H}_{2} \mathrm{O}_{\mathrm{r}}\right) / E_{i}$, similar to the method used for the $\mathrm{NO}_{\mathrm{y}}$ observations. Here, $\mathrm{H}_{2} \mathrm{O}_{\mathrm{r}}$ denotes the remaining $\mathrm{H}_{2} \mathrm{O}_{\mathrm{r}}=\mathrm{H}_{2} \mathrm{O}_{\mathrm{g}}+\mathrm{H}_{2} \mathrm{O}_{\mathrm{a}}$ in the cirrus region, and $\mathrm{H}_{2} \mathrm{O}_{\mathrm{a}}\left(\ll \mathrm{H}_{2} \mathrm{O}_{\mathrm{g}}\right)$ denotes the enhanced $\mathrm{H}_{2} \mathrm{O}$ contained in aerosol particles. The particle enhancement factor $E_{i}$ of the FISH instrument is $7-7.5$ depending on aircraft velocity and pressure for the region of particle observation for particles with $r>3 \mu \mathrm{m}$. Gas phase water has not been measured during the cirrus event. Further, cirrus clouds are known to exist at various stages of ice super- and subsaturation. Therefore, we infer $\mathrm{H}_{2} \mathrm{O}_{\mathrm{r}}$ in the cirrus event from measurements of $\mathrm{H}_{2} \mathrm{O}$ above and below the cloud and in regions free of particles with $r>1 \mu \mathrm{m}$ as shown in Sect. 3. We further compare the mean IWC derived from the FISH data to the IWC derived from FSSP observations and address the sensitivity of the results depending on different assumptions on ambient $\mathrm{H}_{2} \mathrm{O}$ concentrations in Sect. 3 .

Outside of clouds, we calculate the frostpoint $T_{i}$ and the ice saturation ratio $S_{i}$, that is the $\mathrm{H}_{2} \mathrm{O}$ vapor pressure divided by the $\mathrm{H}_{2} \mathrm{O}$ partial pressure over ice (Marti and Mauersberger, 1993) from the FISH gas phase measurements. During the cirrus event, we infer $T_{i}$ and $S_{i}$ from $\mathrm{H}_{2} \mathrm{O}_{\mathrm{g}}$. This method introduces a potentially large uncertainty in the determination of $T_{i}$ and $S_{i}$ in particle regions. Nevertheless, it presents a way to estimate $T_{i}$ and $S_{i}$ given that $\mathrm{H}_{2} \mathrm{O}_{\mathrm{g}}$ has not been measured directly on that day.

The molar $\mathrm{HNO}_{3} / \mathrm{H}_{2} \mathrm{O}$ ratio in ice has been derived by dividing $\mathrm{HNO}_{3, \mathrm{i}}$ by IWC in the particle event, both in units 

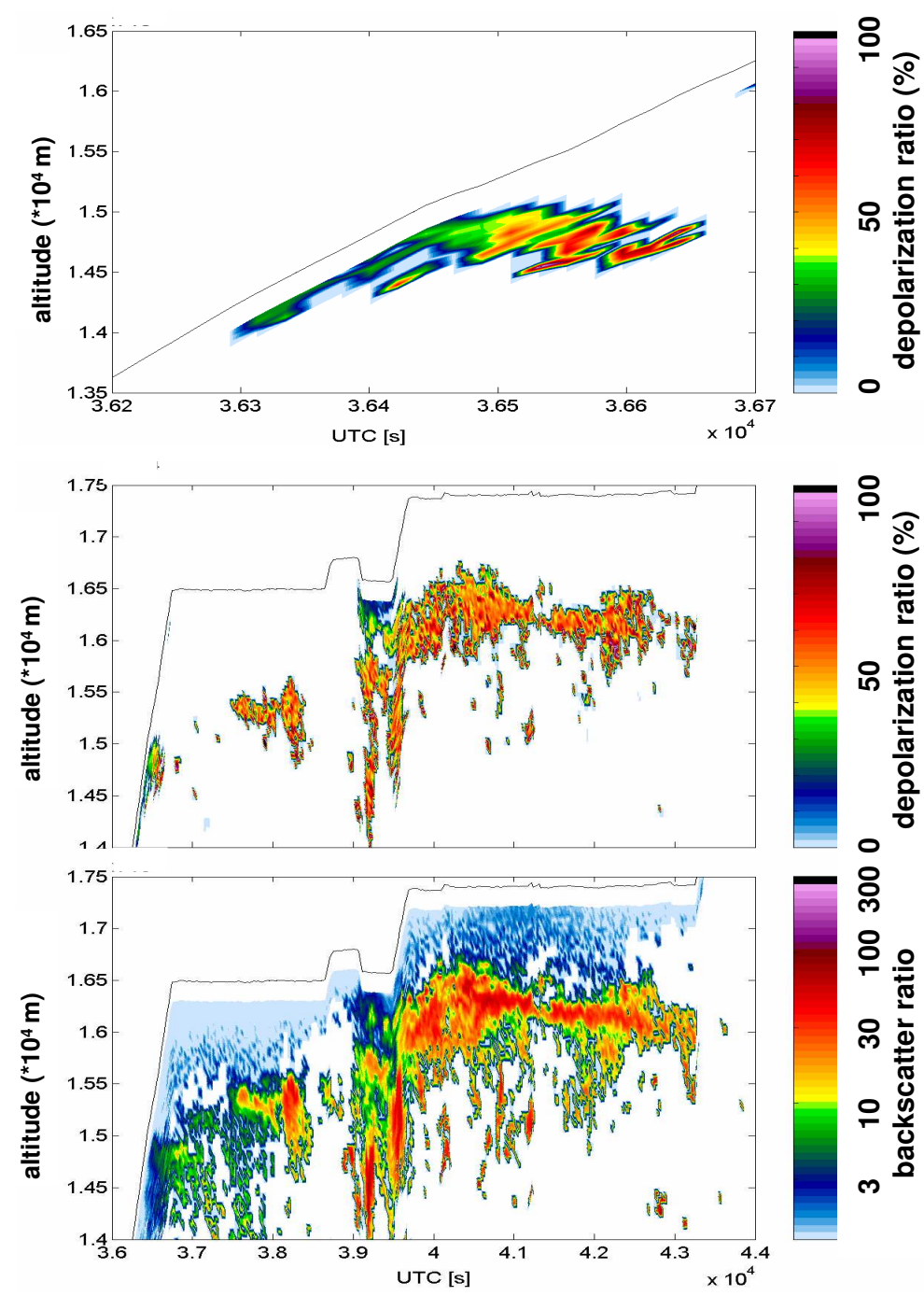

Fig. 1. Backscatter ratios and aerosol depolarization at a wavelength of $532 \mathrm{~nm}$ measured during a Geophysica flight on 17 February 2005 . White regions indicate signal-to-noise ratios less than 1.5. An enhanced view of the depolarization during ascent through a cloud layer is shown in the upper panel.

$\mathrm{nmol} \mathrm{mol}{ }^{-1}$. The error is mainly determined by the determination of $\mathrm{NO}_{\mathrm{y}, \mathrm{r}}$ and $\mathrm{H}_{2} \mathrm{O}_{\mathrm{r}}$ and is quantified in Sect. 3 .

Additional information about the ice particle size distribution and number density has been derived from measurements with a forward scattering spectrometer probe (FSSP100) (Borrmann et al., 2000). The FSSP100 detects light scattered by particles in the diameter range 2.7$29.7 \mu \mathrm{m}$. The detection of only 1 particle within $100 \mathrm{~s}$ by the FSSP would correspond to an ambient particle concentration $1.1 \times 10^{-4} \mathrm{~cm}^{-3}$. To reduce uncertainties related to oscillations in the Mie scattering efficiency (roughly $2-8 \mu \mathrm{m}$ particle size), some of the 30 channels from the original configuration have been merged, resulting in a coarser size resolution based on 7 channels.
For comparison with FISH data, we calculate the ice water content from the observed particle size distribution. Thereby we neglect the IWC of particles with $r_{i}<1.35 \mu \mathrm{m}$ because these particles are not measured by the FSSP. Such small ice particles may change the IWC by less than $1 \%$. The error in the IWC derived from the FSSP data is determined by the error due to counting statistics of $\pm 35 \%$ in the present case, by the uncertainty in the sampling volume of $25 \%$, and the uncertainty in the Mie scattering in the particle size range between 2 and $8 \mu \mathrm{m}$. In addition, the particle number density might be underestimated by the FSSP while measuring during ascent, this error has not been quantified at present. Hence in addition to the size information derived from FSSP measurements, we concentrate the following analysis on the IWC derived from FISH data. 


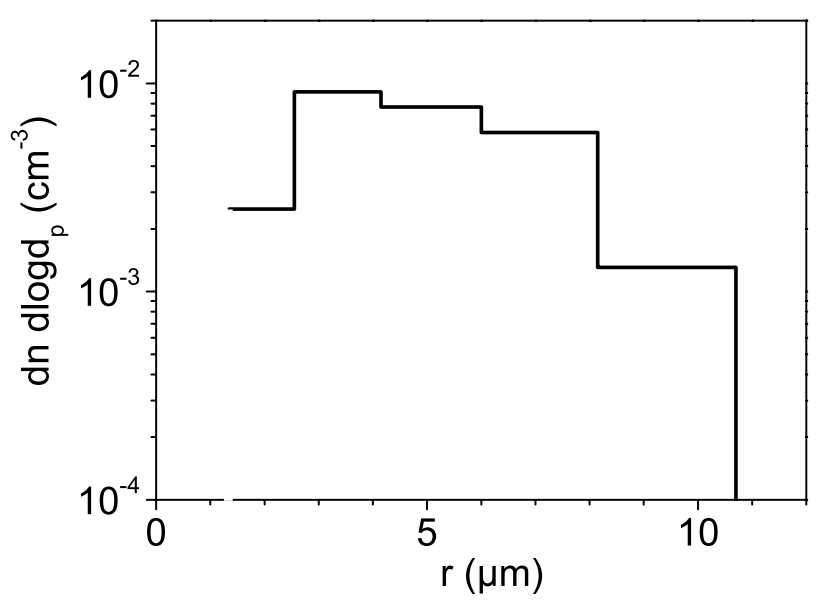

Fig. 2. Particle size distribution inferred from FSSP100 data averaged over the cirrus encounter. Particles with radii $r<1.35 \mu \mathrm{m}$, if present, cannot be detected by the FSSP; particles with $r>10.7 \mu \mathrm{m}$ were not measured.

Backscatter ratios and volume depolarization of subvisible cirrus clouds and the altitude of the top of opaque clouds have been determined with a miniature aerosol lidar Mark 2 (MAL) instrument onboard the Geophysica (Mitev et al., 2002). The automated lidar measured downwards at an operational wavelength of $532 \mathrm{~nm}$. The time and altitude resolution of the lidar data are $21 \mathrm{~s}$ and $43 \mathrm{~m}$, respectively. The presentation of the lidar observation range starts $200 \mathrm{~m}$ below the aircraft to the ground, depending on the cloud thickness. Enhanced volume depolarization indicates the presence of aspherical particles.

The temperature was measured with an accuracy of $\pm 0.6 \mathrm{~K}$ with a PT100 thermistor. Comparisons with a Rosemount sensor onboard the Geophysica show that the Rosemount data are on average $0.2 \mathrm{~K}$ warmer than the PT100 data.

\section{Observations}

\subsection{Particle properties and water}

The Geophysica crossed an optically thin particle layer between 14.2 and $15 \mathrm{~km}$ altitude (near $140 \mathrm{mb}$ ) during its ascent. Vertical cross sections of particle backscatter ratios and depolarization detected with the downward looking lidar are shown in Fig. 1. Low backscatter ratios $(<5)$ combined with enhanced volume depolarization $(>20 \%)$ demonstrate the presence of aspherical particles within the cloud layer (upper panel in Fig. 1). White areas indicate regions with a signal-to-noise ratio of the lidar data $<1.5$, therefore no data are available there.

The particle size distribution in this particle layer is depicted in Fig. 2. To obtain reasonable counting statistics (62 particles have been detected), the FSSP data are averaged over the total measurement time in the particle layer. From the FSSP particle size distribution, we derive a total particle number density $n_{i}=0.005 \mathrm{~cm}^{-3}$, and a mean spherical radius $r_{i}=5 \mu \mathrm{m}$. The bin containing the mean value is $1.9 \mu \mathrm{m}$ wide, so the mean is uncertain by $\pm 0.95 \mu \mathrm{m}$. The statistical error in the ice crystal number density is $\pm 12 \%$. However, due to anisokinetic sampling during ascent, we regard the ice crystal number density as a lower estimate.

In the vicinity of the layer, liquid particles (red and orange colors in the backscatter plot) have been observed in a convective system with embedded cirrus (yellow and red colors in the depolarization plots, detected from 37600 to 43300 s UT). The convective system with similar optical particle properties has also been identified in quasi-simultaneous measurements with the lidar onboard the DLR Falcon parallel about $200 \mathrm{~km}$ away from the flight track (C. Kiemle, personal communication, 2006). High concentrations of carbon monoxide (up to $125 \mathrm{nmol} \mathrm{mol}^{-1}$ ), low ozone concentrations $\left(<40 \mathrm{nmol} \mathrm{mol}^{-1}\right)$, and an enhanced fraction of nonvolatile condensation nuclei ( $>20 \%$ ) suggest some convective influence also in the depolarizing layer.

The lidar data of the Falcon combined with the Geophysica data set suggest that the Geophysica ascended through the boundary region of a convective cloud. Although updraft speeds have not been measured, it is conceivable that the probed region was dynamically active, setting the stage for freezing of aerosol particles. As a major part of the layer was supersaturated with respect to ice (see below), ice crystals could nucleate and grow by deposition of $\mathrm{H}_{2} \mathrm{O}$. Figure 3 shows the time series of particle measurements within the particle layer taken with the $\mathrm{NO}_{\mathrm{y}}$ and the FISH instrument as well as the FSSP100.

Note that the $\mathrm{NO}_{\mathrm{y}}$ and the FISH instruments have much higher sampling volumes than the FSSP, hence we refrain from a discussion of time resolved data, because the measurement time in this transient cloud region was naturally limited. In the following, we concentrate on data taken in ice supersatured regions of the cloud to focus on active ice growth regions. Hence we express all measured quantities as mean values averaged over the $700 \mathrm{~m}$ thick layer with $S_{i}>1$ (36 302-36397 s UT).

Particles have been detected in the ice supersaturated layer at a mean temperature $T=202.4 \mathrm{~K}$ (observed range 200.9-204.6 K). Temperatures in the layer were on average $0.8 \mathrm{~K}$ below $T_{i}$ (inferred range $201.5-204.8 \mathrm{~K}$ ) and on average $11 \%$ supersaturated with respect to ice (inferred range $1<S_{i}<1.23$ ).

Figure 4 displays the temperature, $T_{i}$, particulate water derived from FISH data and particulate nitric acid derived from $\mathrm{NO}_{\mathrm{y}}$ data as a function of altitude. The particle layer with $S_{i}>1$ extends over altitudes of $14.2-14.9 \mathrm{~km}$.

The depolarization, the supersaturation with respect to ice, and $r_{i}$ typically too large for aerosol particles at this altitude all suggest that the particles were primarily composed of 


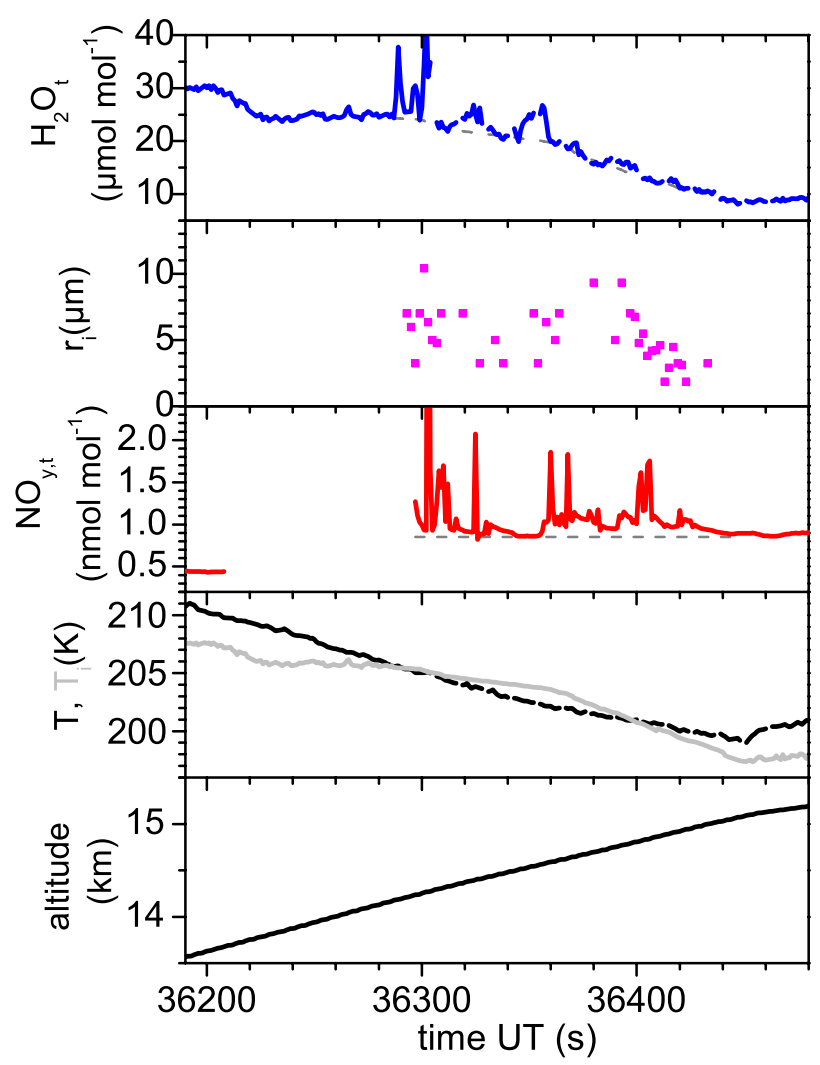

Fig. 3. Time series of total $\mathrm{H}_{2} \mathrm{O}_{t}$, mean particle radii, total $\mathrm{NO}_{\mathrm{y}, \mathrm{t}}$, $T, T_{i}$ and altitude measured on 17 February 2005 during ascent from Araçatuba $\left(19.7^{\circ} \mathrm{S}, 50.2^{\circ} \mathrm{W}\right.$, Brazil). Spikes in the $\mathrm{NO}_{\mathrm{y}}$ and $\mathrm{H}_{2} \mathrm{O}$ signals indicate the presence of $\mathrm{HNO}_{3, \mathrm{i}}$ in ice crystals. $\mathrm{NO}_{\mathrm{y}, \mathrm{t}}$ and $\mathrm{H}_{2} \mathrm{O}_{\mathrm{t}}$ data are not corrected for particle enhancement. The gray lines are estimates for $\mathrm{NO}_{y}, \mathrm{r}$ and $\mathrm{H}_{2} \mathrm{O}_{\mathrm{r}}$ in the particle layer.

water ice. The FISH data yield an IWC of only $0.031 \mathrm{mg} / \mathrm{m}^{3}$ $\left(0.21 \mu \mathrm{mol} \mathrm{mol}^{-1}\right)$ of equivalent particulate $\mathrm{H}_{2} \mathrm{O}$. The IWC derived from the FSSP particle size distribution is a factor of 10 lower, which might be explained either by a reduced sampling efficiency of the FSSP during ascent, or by the presence of very low concentrations of particles with radii $r>30 \mu \mathrm{m}$, which cannot be detected by the FSSP100. As an example, the presence of $6 \times 10^{-5}$ ice particles per $\mathrm{cm}^{3}$ of air with $r_{i} \sim 50 \mu \mathrm{m}$ could explain that difference. However, according to the lidar observations, ice particles have not been detected above the depolarizing layer, ruling out that large ice crystals might have sedimented from above into the probed layer.

We compare IWC and mean $r_{i}$ to values of cirrus clouds more typical for developed clouds. A climatology derived from combined lidar and radar measurements of cirrus cloud properties yields an effective spherical radius of $11.9 \mu \mathrm{m}$ and an IWC of $1.15 \mathrm{mg} / \mathrm{m}^{3}$ at $202 \mathrm{~K}$ (Wang and Sassen, 2002). Such values typical for aged cirrus by far exceed those from the present observations.

Based on this combined evidence, our working hypothesis is that the Geophysica coincidentally probed a cirrus layer

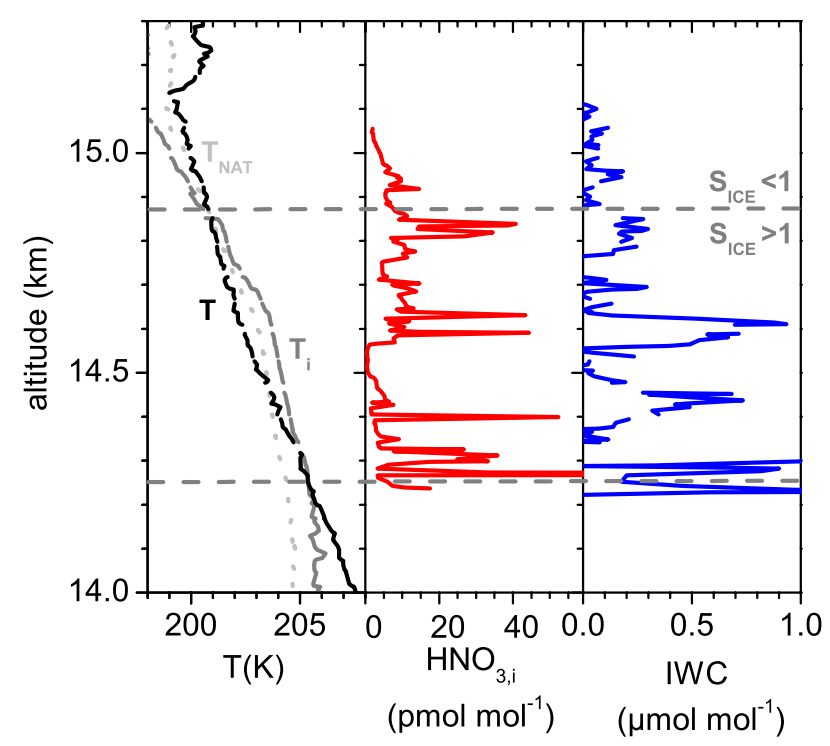

Fig. 4. Vertical profiles of $T, T_{\mathrm{NAT}}, T_{i}$, particle $\mathrm{HNO}_{3}$ and IWC during ascent through the cirrus cloud.

in its formation stage. Tropical ultrathin cirrus clouds have similar ice particle properties, but have a vast horizontal extension, are concentrated in very thin vertical layers, and require a stabilization mechanism tied to weak vertical uplifts (of order $\mathrm{mm} / \mathrm{s}$ ) to persist (Peter et al., 2003; Luo et al., 2003). It is very unlikely that such clouds would form and persist contiguous to a convective system. We cannot rule out that ice particles originated from detrainment of air parcels from the convective region nearby, but we think that this scenario is less plausible than our working hypothesis, which is also supported by model simulations presented in Sect. 4.2.

As details of the dynamical evolution of the probed layer are not known, ice formation and growth could have continued (the number of crystals and their average size increased) or ice formation could already have been completed at the time of observation. Regardless, in-situ evidence of ice crystals in cirrus formation regions is very rare, underscoring the value of the measurements presented in our study.

\subsection{Nitric acid partitioning}

Figures 3 and 4 also show $\mathrm{NO}_{\mathrm{y}}$ in the ice cloud layer. The gap in the $\mathrm{NO}_{\mathrm{y}}$ time series between 36210 and $36302 \mathrm{~s} \mathrm{UT}$ is due to a switch of the instrument mode to determine the instrumental background. Nitric acid containing ice particles are detected between 36302 and $36450 \mathrm{~s}$ UT, as indicated by spikes in the $\mathrm{NO}_{\mathrm{y}, \mathrm{t}}$ signal. There is a good correlation between the $\mathrm{NO}_{\mathrm{y}, \mathrm{t}}, \mathrm{H}_{2} \mathrm{O}_{\mathrm{t}}$ and the FSSP100 data.

In cirrus with sufficiently high IWC $\left(>0.1-1 \mathrm{mg} \mathrm{m}^{-3}\right)$ in the absence of very high ice supersaturations, $\mathrm{HNO}_{3}$ is redistributed between aerosol and ice particles and uptake in ice dominates dissolution in liquid particles (Kärcher, 2005; 


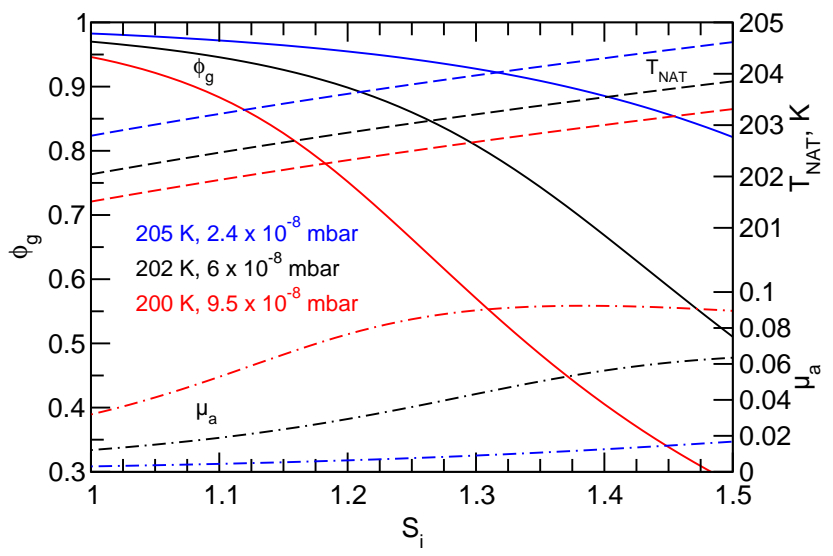

Fig. 5. Thermodynamic equilibrium properties of STS aerosol particles containing $0.1 \mathrm{nmol} \mathrm{mol}^{-1} \mathrm{H}_{2} \mathrm{SO}_{4}$ as a function of the ice saturation ratio $S_{i}$ for various combinations of the $\mathrm{HNO}_{3}$ partial pressure $p_{n}$ and $T$ prevailing during the TROCCINOX observations. Shown is the fraction $\phi_{g}$ of $\mathrm{HNO}_{3}$ remaining in the gas phase (solid) and the aerosol molar $\mathrm{HNO}_{3} / \mathrm{H}_{2} \mathrm{O}$ ratio $\mu_{a}$ (dot-dashed). The NAT existence temperature $T_{\text {NAT }}$ is also given (dashed).

Krämer et al., 2006). This would justify the neglect of a significant amount of $\mathrm{HNO}_{3}$ in liquid aerosol particles, at least in STS particles, an assumption frequently used in previous analyses of $\mathrm{HNO}_{3}$ uptake in cirrus. The situation during TROCCINOX, however, is different, inasmuch as only few, very small ice crystals have been measured. This raises the question whether $\mathrm{HNO}_{3}$ could have been present in STS particles sampled in the forward facing inlet, besides $\mathrm{HNO}_{3, \mathrm{i}}$. Our thermodynamic calculations shown in Fig. 5 demonstrate that $5 \%$ of $\mathrm{HNO}_{3, \mathrm{~g}}$ is present in aerosol at the mean observation conditions (black $\phi_{g}$-curve at $S_{i}=1.11$ ). Similar conditions prevail in the cloud region detected between 36339 to $36351 \mathrm{~s}$ UT, where large particles $(r>1 \mu \mathrm{m})$ were absent. To avoid interference of $\mathrm{HNO}_{3, \text { a }}$ with $\mathrm{HNO}_{3, \mathrm{i}}$, we attribute $\mathrm{HNO}_{3, \mathrm{a}}$ to $\mathrm{NO}_{\mathrm{y}, \mathrm{r}}$ as described in Sect. 2.

We further derive a mean $\mathrm{HNO}_{3, \mathrm{i}}$ content in ice particles of $11 \mathrm{pmol} \mathrm{mol}^{-1}$ for an estimated rest $\mathrm{NO}_{\mathrm{y}, \mathrm{r}}$ of $0.85 \mathrm{nmol} \mathrm{mol}^{-1}$ in the cirrus region (see Fig. 3). Maximum values $>56 \mathrm{pmol} \mathrm{mol}^{-1} \mathrm{HNO}_{3, \mathrm{i}}$ are found in the particle layer.

Integration over the ice supersaturated layer yields an $\mathrm{HNO}_{3} / \mathrm{H}_{2} \mathrm{O}$ molar ratio $\mu$ in ice of $5.4 \times 10^{-5}$, by far exceeding previous observations in cirrus clouds at similar temperatures (Voigt et al., 2006). The error of the $\mathrm{HNO}_{3} / \mathrm{H}_{2} \mathrm{O}$ molar ratio is mainly determined by the uncertainty in $\mathrm{NO}_{\mathrm{y}, \mathrm{r}}$ and $\mathrm{H}_{2} \mathrm{O}_{\mathrm{r}}$. The lower bound of $3.7 \times 10^{-5}$ of the $\mathrm{HNO}_{3} / \mathrm{H}_{2} \mathrm{O}$ molar ratio in ice is given by the uncertainty in $\mathrm{H}_{2} \mathrm{O}_{\mathrm{r}}$. An upper limit of $8.5 \times 10^{-5}$ has been derived from a sensitivity analysis of $\mathrm{HNO}_{3, \mathrm{r}}$.
A comparison of particle properties in the layer with $S_{i}>1$ with particle data in sub-saturated conditions (36398$36450 \mathrm{~s}$ UT) shows that ice particles at $S_{i}<1$ are slightly smaller and have a lower ice water content, indicative for ice crystal evaporation. As a sensitivity study, we additionally integrated the data over the total cloud layer independent of $S_{i}$. In the ice supersaturated layer, the $\mathrm{HNO}_{3} / \mathrm{H}_{2} \mathrm{O}$ molar ratio in ice of $5.4 \times 10^{-5}$ is slightly higher compared to the average of the total particle layer $\left(5.0 \times 10^{-5}\right)$, and within the experimental uncertainty given above. The IWC of $0.031 \mathrm{mg} \mathrm{m}^{-3}$ in the supersaturated cloud layer is slightly higher but within the experimental error compared to the IWC of the total particle layer of $0.026 \mathrm{mg} \mathrm{m}^{-3}$.

Despite the large uncertainty in the $\mathrm{HNO}_{3} / \mathrm{H}_{2} \mathrm{O}$ molar ratio in ice, the combined evidence of the high $\mathrm{HNO}_{3}$ content of the ice particles, low IWC, small ice crystal sizes and number densities suggest that this cirrus cloud layer may have been probed in its formation stage. This working hypothesis will be supported by model simulations presented in Sect. 4.2.

Airborne observations over the eastern Pacific revealed the existence of $\mathrm{HNO}_{3}$-containing particles in the tropical lower stratosphere, most likely composed of the nitric acid trihydrate (NAT) (Popp et al., 2006). Although particulate water has not been measured in that case, the derived particle mass mixing ratio assuming NAT composition is significantly lower and hence those particles were distinctly different from the particles detected during TROCCINOX.

The TROCCINOX particle layer has been observed at temperatures near and below the NAT equilibrium temperature $T_{\mathrm{NAT}}\left(T_{\mathrm{NAT}}-1.5 \mathrm{~K}<T<T_{\mathrm{NAT}}+1.1 \mathrm{~K}\right)$ shown in Fig. 4 , calculated after Hanson and Mauersberger (1988). As the TROCCINOX observations were taken close to NAT existence conditions, the observed particles may have been present in the form of $\Delta$-ice (Gao et al., 2004).

\section{Modeling}

We show that the comparatively high $\mathrm{HNO}_{3} / \mathrm{H}_{2} \mathrm{O}$ molar ratios $\mu=(3.7-8.5) \times 10^{-5}$ measured within the layer (see Sect. 3.2) can be explained by uptake of $\mathrm{HNO}_{3}$ in STS particles, homogeneous freezing of these particles, and subsequent depositional growth of ice crystals combined with trapping of ambient available $\mathrm{HNO}_{3}$. We also estimate ranges of $\mu$-values the cloud would have obtained in a developed stage. Only then the TROCCINOX data are comparable with previous measurements of $\mathrm{HNO}_{3}$ uptake in cirrus clouds. In a second step, we perform additional time-dependent simulations to learn more about the phase partitioning of $\mathrm{HNO}_{3}$, particle properties, and time scales involved. 


\subsection{Steady-state analysis}

The steady-state molar $\mathrm{HNO}_{3} / \mathrm{H}_{2} \mathrm{O}$ ratio in ice particles can be split into two components (Kärcher and Voigt, 2006)

$\mu=\mu_{a} \frac{1}{1+N}+\mu_{\infty} \frac{N}{1+N}, \quad N=\frac{\rho_{i}}{\rho}\left(\frac{r_{i}}{r}\right)^{3}$,

where $\mu_{a}$ is the molar ratio in frozen STS particles, originating from uptake of $\mathrm{HNO}_{3}$ in aqueous sulfuric acid solution droplets during cooling prior to freezing; $\mu_{\infty}$ is the portion of ambient $\mathrm{HNO}_{3}$ trapped during ice particle growth; and $N$ is a growth factor describing the amount of water taken up by the ice particles (bulk density $\rho_{i}$ ) of actual radius $r_{i}$ relative to the water content present in the freezing aerosol particles (composition-dependent bulk density $\rho$ ) of radius $r \leq r_{i}$. Because $\mu \ll 1, \mathrm{HNO}_{3}$ molecules associated with ice particles do not change the bulk properties of ice.

Right after freezing, we have $N=0$ and obtain the initial value $\mu=\mu_{a}$ from Eq. (1). After a short ice particle growth stage, $\mu \propto \mu_{a}\left(r / r_{i}\right)^{3}$. In the fully developed cloud, the second term on the right hand side of Eq. (1) takes over, and $\mu \approx \mu_{\infty}$ becomes constant. Fully developed clouds are defined by prescribing a typical mean spherical radius $r_{i}(T)$ derived from a series of remote sensing observations (Wang and Sassen, 2002). Below we use $r_{i}$ also as a parameter to illustrate how $\mu$ changes during ice particle growth. The overall results are sensitive to variations of the gasphase nitric acid partial pressure $p_{n}$, because $\mu_{a}$ rises strongly with $p_{n}$ (see Fig. 5) and $\mu_{\infty} \propto p_{n}$.

The aerosol molar ratio $\mu_{a}$ is computed by assuming an equilibrium composition of the STS particles at $202 \mathrm{~K}$ and $140 \mathrm{mb}$ (see Fig. 5), homogeneous freezing saturation ratio over ice (1.57), estimated sulfuric acid content in STS aerosol $\left(q_{s}=0.1 \mathrm{nmol} \mathrm{mol}^{-1}\right)$, a freezing particle radius $r=0.5 \mu \mathrm{m}$, and a range of $\mathrm{HNO}_{3}$ partial pressures $p_{n}=(2.4-9.5) \times 10^{-8} \mathrm{mb}$ representing $20-80 \%$ of the measured mean $\mathrm{NO}_{\mathrm{y}, \mathrm{r}}$ from Sect. 3.2. Further, $\mu_{a}$ is reduced by a factor 0.4 , accounting for possible deviations from the equilibrium composition and/or possible release of dissolved $\mathrm{HNO}_{3}$ during freezing. Apart from the lower air pressure (to which the results are not sensitive) and higher $p_{n}$, these parameters are identical to Kärcher and Voigt (2006). The impact of higher $p_{n}$ values is discussed below.

The ambient molar ratio $\mu_{\infty}$ is given by the ratio of diffusive molecular fluxes of $\mathrm{HNO}_{3}$ and $\mathrm{H}_{2} \mathrm{O}$ toward ice particles. It is proportional to the efficiency $\epsilon$ by which $\mathrm{HNO}_{3}$ is trapped in the growing ice particles. The trapping efficiency increases as $T$ decreases (Kärcher and Voigt, 2006), and has been constrained by comparison to a large body of field measurements of the $\mathrm{HNO}_{3} / \mathrm{H}_{2} \mathrm{O}$ ratio in cirrus (Voigt et al., 2006):

$\epsilon=\frac{\beta}{1+(1-\beta) \xi}$,

where $\beta$ is a size-dependent correction modifying the diffusive flux of $\mathrm{HNO}_{3}$ at high Knudsen numbers; it contains the

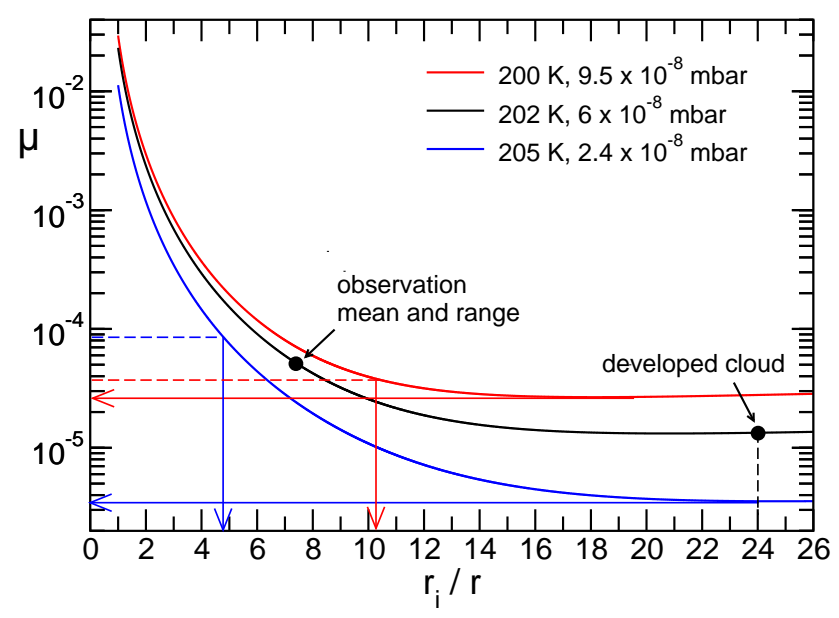

Fig. 6. Steady-state molar $\mathrm{HNO}_{3} / \mathrm{H}_{2} \mathrm{O}$ ratios $\mu$ in ice (curves) versus normalized ice crystal spherical radius $r_{i} / r$. Curves are evaluated for $r=0.5 \mu \mathrm{m}$ and upper and lower limit $\mathrm{HNO}_{3}$ partial pressures at various $T$ and $p=140 \mathrm{mb}$. Observation taken during TROCCINOX while probing an ice supersaturated region. Range of observed $\mu$-values leads to the range of ice particle radii bounded by the vertical arrows. The radius marked by "developed cloud" is based on a cirrus climatology at $202 \mathrm{~K}$ and yields an approximate range of molar ratios the probed cloud would have obtained after a typical aging period (horizontal arrows).

$\mathrm{HNO}_{3}$ mass accommodation coefficient on ice $\alpha=0.3$ (Hanson, 1992). The parameter $\xi(T)$ is defined as the ratio of the effective speed with which adsorbed $\mathrm{HNO}_{3}$ molecules leave the ice particle surface (and are not trapped) relative to the speed at which the ice particle surface grows and potentially traps $\mathrm{HNO}_{3}$.

The resulting evolution of $\mu$ is displayed in Fig. 6 (curves corresponding to the mean $\bar{p}_{n}=6 \times 10^{-8} \mathrm{mb}$ and to the low and high $p_{n}$-limits), along with the observed value $\mu_{\mathrm{obs}}=5 \times 10^{-5}$ (left black circle). Below $r_{i} / r=10-12$, the model curves are governed by the early growth solution. Above $r_{i} / r=12$, the model curves start to be governed by the asymptotic solution $\mu_{\infty}$.

Our model with $r=0.5 \mu \mathrm{m}$ gives $r_{i} \approx 3.7 \mu \mathrm{m}$ for the observed $\mu \approx 5 \times 10^{-5}$ (left black circle). The horizontal dashed lines mark the range of radii $\left(r_{i}=2.4-5.1 \mu \mathrm{m}\right)$ consistent with the observations as bounded by the vertical arrows. These values are within the range of particle radii detected by the FSSP100 (see Fig. 2). Recall, however, that the analysis of crystal sizes with this instrument is rather uncertain in this size range and that the steady-state model fixes one size of freezing particles while in reality, particles from a range of sizes will freeze. Fortunately, the solution at small $r_{i} / r$ is rather insensitive to changes in $r$.

Figure 6 also predicts the $\mu$-values the TROCCINOX cloud would have obtained if the data had been taken at the same temperature and pressure after aging to developed cloud conditions. The corresponding mean radius is $\sim 12 \mu \mathrm{m}$ 

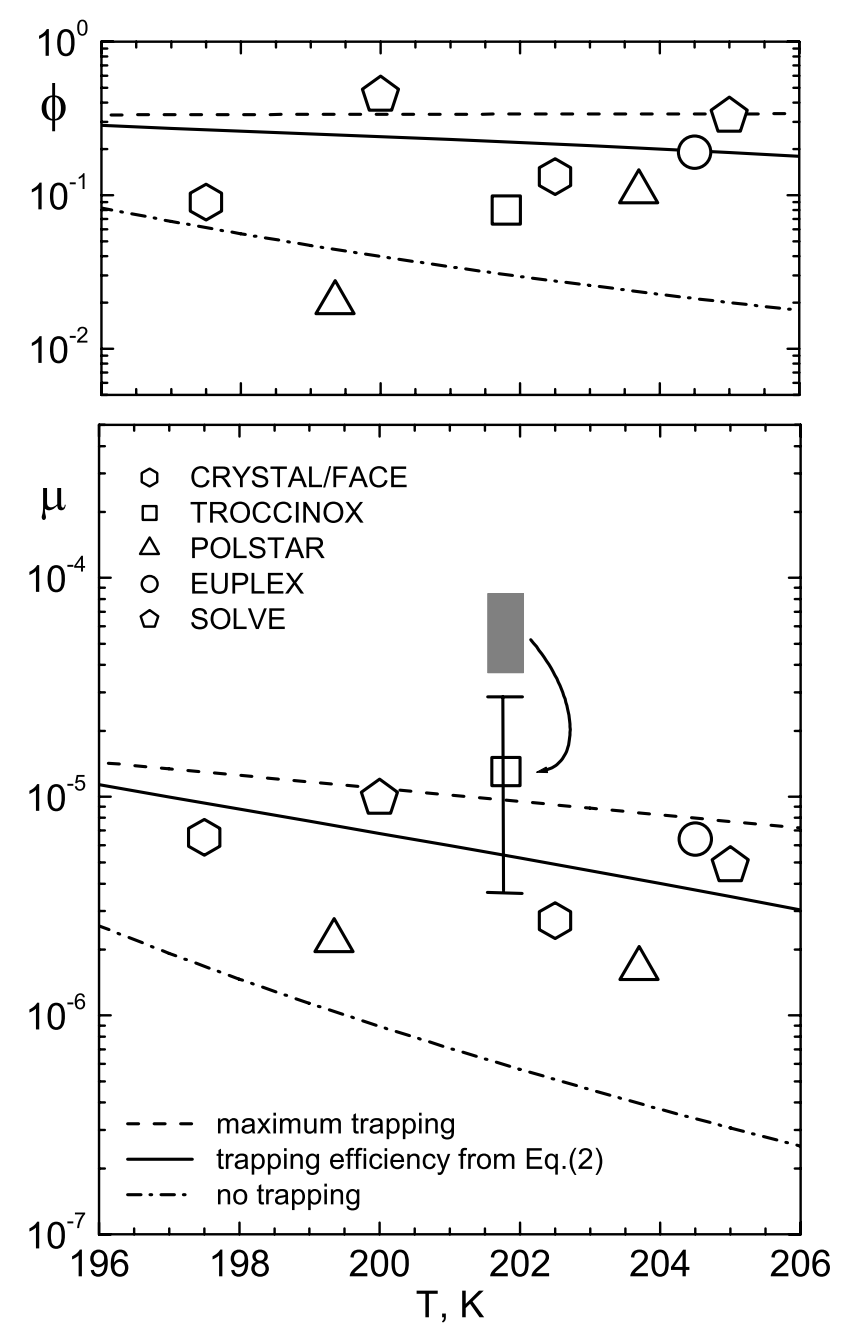

Fig. 7. The bottom panel depicts the TROCCINOX observations of molar $\mathrm{HNO}_{3} / \mathrm{H}_{2} \mathrm{O}$ ratio $\mu$ (gray) and the mean value (square) estimated from Fig. 6 after typical cloud aging. The observational uncertainty range is indicated by the vertical extent of the gray area, those from the estimates by the error bar $(\mu)$. For comparison, selected results in the low temperature region are shown from previous campaigns (legends) (Voigt et al., 2006). The curves denote approximate upper (dashed) and lower (dot-dashed) values along with a best estimate (solid) for average $\mu$ based on the trapping model (Kärcher and Voigt, 2006). The TROCCINOX $\mu$ data point lies above the upper limit curve because the $\mathrm{HNO}_{3}$ partial pressure during TROCCONIX was on average three times higher than the value adopted to calculate the curves. The top panel displays the corresponding mean ice phase fraction $\phi$ of $\mathrm{HNO}_{3}$ estimated in the case of TROCCINOX and inferred from the other observations.

(vertical dashed line); the right black circle and the horizontal arrows bound the resulting best estimate $\left(1.3 \times 10^{-5}\right)$ and range $\left(3.5 \times 10^{-6}-2.5 \times 10^{-5}\right)$ of estimated $\mu$-values.

The above analysis suggests consistency between the TROCCINOX data and other field data after the TROCCINOX measurements have been projected to a developed cloud stage using the trapping model. We also derive the steady-state fraction of $\mathrm{HNO}_{3}$ in the ice phase $\phi$ using the trapping equations, which can be expressed in terms of $\mu, p_{n}$, and IWC (Kärcher and Voigt, 2006). We find a mean value $\phi \approx 0.08$. These results are displayed in Fig. 7, where we show the range of $\mu$-values from the current measurements (gray rectangle) and the estimated $\mu$ - and $\phi$-values after cloud aging (squares). Selected results from previous campaigns in the low $T$-region (other symbols, taken from Voigt et al. (2006)) and the results from the steady-state model (curves, reproduced from Kärcher and Voigt (2006) consistent with Eqs. (1) and (2)) are shown for comparison.

The curves shown in Fig. 7 represent approximate average upper limits (dashed, $\epsilon=\beta$ ) and lower limits (dot-dashed, $\epsilon=0)$ for $\mu$ and $\phi$. The solid curves describing best the average behavior are based on $\epsilon$ from Eq. (2). They have been calculated using $\bar{p}_{n}=2 \times 10^{-8} \mathrm{mb}$. Because the $p_{n}$-range during TROCCINOX exceeded $\bar{p}_{n}$ by a factor of $1.2-4.75$, with a mean of $6 \times 10^{-8} \mathrm{mb}$, the uncertainty bar lies above the upper limit $\mu$-curve in Fig. 7 (recall that $\mu$ increases with $p_{n}$ ). A larger data scatter of $\phi$ around the curves is expected, because this variable depends on the local $p_{n}$, which may be totally uncorrelated with trapping at the time of observation.

\subsection{Microphysical simulations}

The TROCCINOX observation provides a first opportunity to compare observations to microphysical simulations of cloud formation, including trace gas uptake. In what follows we make use of a one-dimensional, cirrus cloud-resolving model with detailed STS aerosol and ice microphysics (Kärcher, 2005).

The coupled uptake of $\mathrm{HNO}_{3}$ and $\mathrm{H}_{2} \mathrm{O}$ in aerosols is treated by simulating gas diffusion toward and dissolution into STS particles discretized into fixed initial size bins. Their growth is followed in a Lagrangian manner, i.e., the particles attain their exact sizes during growth while memorizing the $\mathrm{H}_{2} \mathrm{SO}_{4}$ core sizes. The model tracks the depositional growth, sedimentation, and uptake of $\mathrm{HNO}_{3}$ in many thousand individual ice particles, and is therefore ideally suited to study trapping. Trapping is calculated by integrating the $\mathrm{HNO}_{3}$ diffusive flux toward each growing and falling ice particle using the trapping efficiency from Eq. (2) (Kärcher and Basko, 2004).

The overall meteorological conditions that have been prevailing during the ascent of the Geophysica are not well known and cannot be adopted with certainty from weather forecast models, in particular the transient, highly localized vertical wind fields. Instead we must rely on reasonable assumptions to initialize the simulations. To this end, we prescribe vertical profiles of $T, p$, ice saturation ratio $S_{i}$, and potential temperature as a function of altitude to roughly represent the conditions prevailing during the observations (Sect. 3 and Fig. 4). For $\mathrm{HNO}_{3}$, we adopt a constant mixing ratio of $0.425 \mathrm{nmol} \mathrm{mol}^{-1}$ (the mean $\bar{p}_{n}$ at $140 \mathrm{mb}$ ), 
i.e., $50 \%$ of the inferred $\mathrm{NO}_{\mathrm{y}, \mathrm{g}}$. Cooling is driven by a constant adiabatic updraft speed of $1 \mathrm{~cm} \mathrm{~s}^{-1}$ with superimposed small-scale temperature fluctuations with amplitudes of $0.1 \mathrm{~K}$ (Hoyle et al., 2005). Although the choice of the amplitude and the underlying frequency spectrum of fluctuations is debatable when applied to this specific case, the traces of $T$ agree better with aircraft observations of smallscale structure than without including them. The vertical resolution of the model is $1 \mathrm{~m}$, ice crystals are assumed to be spherical and retain all $\mathrm{HNO}_{3}$ molecules upon freezing. With this setting, we simulate multiple homogeneous freezing events within a layer between 14 and $15 \mathrm{~km}$, resulting in ice particle concentrations within the range $0.01-0.1 \mathrm{~cm}^{-3}$. This range is above the lower limit value derived from the FSSP100 data (see Sect. 3.1); given the measurement uncertainty, the simulations are not necessarily in conflict with the data.

Figure 8 shows the molar $\mathrm{HNO}_{3} / \mathrm{H}_{2} \mathrm{O}$ ratios in selected individual ice particles as a function of their actual radius normalized by their initial radius. Different colors label different times after the first ice crystals formed, ranging from $30 \mathrm{~s}$ to $10 \mathrm{~min}$. At $30 \mathrm{~s}$, a few ice crystals have formed and some of them have already increased their initial size by a factor of 4 . They start growing with high $\mu$-values of order 0.02 , equal to the molar ratio in the STS droplets at the time of freezing. (In the calculation, the STS particles are not necessarily in equilibrium with gas phase $\mathrm{HNO}_{3}$.) In the course of time, the crystals grow further and $\mu$ decreases in larger particles, in very good agreement with the steady-state approach shown in Fig. 7 (Eq. 1). As new particles continue to nucleate, small crystals with high $\mu$ also exist at later stages. After 10 min, simulated ice particle radii range between 1$10 \mu \mathrm{m}$ (not shown), agreeing with the range indicated by the FSSP100 data from Fig. 2. Together, this supports our working hypothesis from Sect. 3.1 that the observed ice crystals formed a few minutes prior to detection.

At $10 \mathrm{~min}$, the air containing ice particles is still highly supersaturated on average $\left(S_{i}>1.4\right)$, while the observations indicate relaxation toward saturation, see Fig. 4. A simple explanation would be that the actual vertical wind field had a wave structure not included here, with a warming phase following the freezing events. This would have caused the supersaturation to decrease faster than by depositional growth alone, which is rather slow at these low ice particle concentrations and sizes. An alternative would be heterogeneous ice nucleation on nuclei forming ice at low supersaturations, for instance in the immersion freezing mode. This process would not significantly change Fig. 8 provided the ice nuclei dissolved a similar amount of $\mathrm{HNO}_{3}$ prior to freezing to guarantee high initial molar ratios.

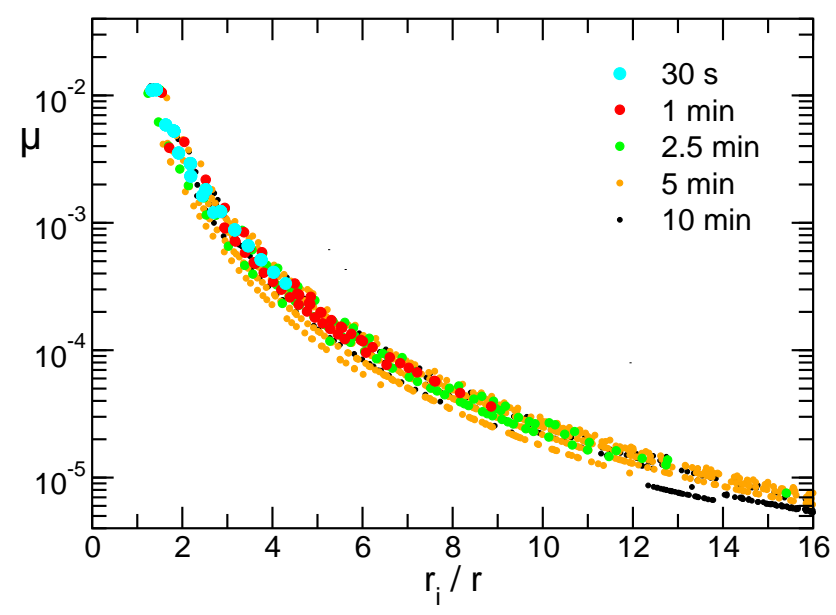

Fig. 8. As Fig. 6, but resulting from a one-dimensional cloudresolving simulation in which STS aerosols can dissolve $\mathrm{HNO}_{3}$ and $\mathrm{H}_{2} \mathrm{O}$ kinetically and freeze homogeneously, and the growth, sedimentation, and $\mathrm{HNO}_{3}$ uptake of individual ice particles are tracked. Shown are selected molar $\mathrm{HNO}_{3} / \mathrm{H}_{2} \mathrm{O}$ ratios in ice particles versus normalized particle radius (symbols) at different times after freezing of the first crystal (see legend). Trajectories of individual crystals (not shown) follow the mean trend indicated by the symbols.

\section{Conclusions}

Molar $\mathrm{HNO}_{3} / \mathrm{H}_{2} \mathrm{O}$ ratios in ice crystals have been reported in an ice cloud layer above Brazil on 17 February 2005. Combined evidence from observational data and microphysical simulations suggest that a nascent ice cloud has been probed. High $\mathrm{HNO}_{3} / \mathrm{H}_{2} \mathrm{O}$ molar ratios in small ice particles (mean radius $5 \mu \mathrm{m}$ ) are found in early cloud stages, decreasing to lower values assuming further ice particles growth.

Measurements in young or thin cirrus clouds are rare; in fact, data with particle surface area densities $<10 \mu \mathrm{m}^{2} \mathrm{~cm}^{-3}$ have been systematically excluded in previous investigations of $\mathrm{HNO}_{3}$ uptake in cirrus clouds (e.g., Kondo et al., 2003; Ziereis et al., 2004; Popp et al., 2004; Voigt et al., 2006). Hence, our observations combined with microphysical modeling presents a first study of ice particle composition during growth. More data are needed particularly at low temperatures to study the competition between aerosol and ice uptake of $\mathrm{HNO}_{3}$ and $\mathrm{H}_{2} \mathrm{O}$ vapor in more detail. To understand the interaction between $\mathrm{HNO}_{3}$ and $\mathrm{H}_{2} \mathrm{O}$ vapor and ice crystals is a requirement to properly assess the role of heterogeneous chemistry in the tropopause region.

Acknowledgements. This work was funded by the European Community within the TROCCINOX and SCOUT-O3 projects. We thank the Geophysica crew for excellent flight operation, A. Roiger and N. Spelten for instrument preparation and B. Luo and P. Popp for helpful comments. The TROCCINOX project coordination by $\mathrm{U}$. Schumann is acknowledged.

Edited by: R. MacKenzie 


\section{References}

Borrmann, S., Solomon, S. Dye, J. E., and Luo, B.: The potential of cirrus clouds for heterogeneous chlorine activation, Geophys. Res. Lett., 23(16), 2133-2136, doi:10.1029/96GL01957, 1996.

Borrmann, S., Thomas, A., Rudakov, A., Yushkov, V., Lepuchov, B., Deshler, T., Vinnichenko, N., Khattatov, V., and Stefanutti, L.: In-situ measurements in the Northern hemispheric stratosphere of the 1996/1997 winter on the Russian M-55 Geophysica high altitude research aircraft, Tellus, 52B, 1088-1103, 2000.

Fahey, D. W., Eubank, C. S., Huebler, G., and Fehsenfeld, F. C.: Evaluation of a catalytic reduction technique, J. Atmos. Chem., 3, 435-468, 1985.

Gao, R. S., Popp, P. J., Fahey, D. W., Marcy, T. P., Herman, R. L., Weinstock, E. M., Baumgardner, D. G., Garrett, T. J., Rosenlof, K. H., Thompson, T. L., Bui, T. P., Ridley, B. A., Wofsy, S. C., Toon, O. B., Tolbert, M. A., Kärcher, B., Peter, Th., Hudson, P. K., Weinheimer, A. J., and Heymsfield, A. J.: Evidence that ambient nitric acid increases relative humidity in low-temperature cirrus clouds, Science, 303, 516-520, 2004.

Gamblin B., Toon, O. B., Tolbert, M. A., Kondo, Y., Takegawa, N., Irie, H., Koike, M., Ballenthin, J. O., Hunton, D. E., Miller, T. M., Viggiano, A. A., Anderson, B. E., Avery, M., Sachse, G. W., Podolske, J. R., Guenther, K., Sorenson, C., and Mahoney, M. J.: Nitric acid condensation on ice: 1 . Non- $\mathrm{HNO}_{3}$ constituent of $\mathrm{NO}_{\mathrm{y}}$ condensing cirrus particles on upper tropospheric, J. Geophys. Res., 111, D21203, doi:10.1029/2005JD006048, 2006.

Hanson, D. and Mauersberger. K., Laboratory studies of the nitric acid trihydrate: Implications for the south polar stratosphere, Geophys. Res. Lett., 15, 855-858, 1988.

Hanson, D. R.: The uptake of $\mathrm{HNO}_{3}$ onto ice, NAT, and frozen sulfuric acid, Geophys. Res. Lett., 19, 2063-2066, 1992.

Hartmann, D. L., Ockert-Bell, M. E., and Michelsen, M. L.: The effect of cloud type on Earth's energy balance: Global analysis, J. Climate, 5, 1281-1304, 1992.

Hoyle, C. R., Luo, B. P., and Peter, Th.: The origin of high ice crystal number densities in cirrus clouds, J. Atmos. Sci., 62, 25682579, 2005.

Kärcher, B.: Supersaturation, dehydration, and denitrification in Arctic cirrus, Atmos. Chem. Phys., 5, 1757-1772, 2005, http://www.atmos-chem-phys.net/5/1757/2005/.

Kärcher, B. and Basko, M. M.: Trapping of trace gases in growing ice crystals, J. Geophys. Res., 109, D22204, doi:10.1029/2004JD005254, 2004.

Kärcher, B. and Voigt, C.: Formation of nitric acid/water ice particles in cirrus clouds, Geophys. Res. Lett., 33, L08806, doi:10.1029/2006GL025927, 2006.

Kondo, Y., Toon, O. B., Irie, H., Gamblin, B., Koike, M., Takegawa, N., Tolbert, M. A., Hudson, P. K., Viggiano, A. A., Avallone, L. M., Hallar, A. G., Anderson, B. E., Sachse, G. W., Vay, S. A., Hunton, D. E., Ballenthin, J. O., and Miller, T. M.: Uptake of reactive nitrogen on cirrus cloud particles in the upper troposphere and lowermost stratosphere, Geophys. Res. Lett., 30, 1154, doi:10.1029/2002GL016539, 2003.

Krämer, M. and Afchine, A.: Sampling characteristics of inlets operated at low $\mathrm{U} / \mathrm{U}_{0}$ ratios: new insights from computational fluid dynamics (CFX) modeling, J. Aerosol Sci., 35, 683-694, doi:10.1016/j.jaerosci.2003.11.011, 2004.

Krämer, M., Schiller, C., Ziereis, H., Ovarlez, J. and H. Bunz (2006): Nitric acid partitioning in cirrus clouds: the role of aerosol particles and relative humidity, Tellus B, 58, 141-147, doi:10.1111/j.1600-0889.2006.00177, 2006.

von Kuhlmann, R., and Lawrence, M. G.: The impact of ice uptake of nitric acid on atmospheric chemistry, Atmos. Chem. Phys., 6, 225-235, 2006,

http://www.atmos-chem-phys.net/6/225/2006/.

Law, K., Pan, L., Wernli, H., Fischer, H., Haynes, P., Salawitch, R., Kärcher, B., Prather, M., Doherty S., and Ravishankara, A. R.: Processes governing the chemical composition of the extratropical UTLS, SPARC Newsletter No. 26, 8-19, 2006.

Luo, B. P., Peter, Th., Wernli, H., Fueglistaler, S., Wirth, M., Kiemle, C., Flentje, H., Yushkov, V. A., Khattatov, V., Rudakov, V., Thomas, A., Borrmann, S., Toci, G., Mazzinghi, P., Beuermann, J., Schiller, C., Cairo, F., Di Donfrancesco, G., Adriani, A., Volk, C. M., Ström, J., Noone, K., Mitev, V., MacKenzie, R. A., Carslaw, K. S., Trautmann, T., Santacesaria, V., and Stefanutti, L.: Ultrathin tropical tropopause clouds (UTTCs): II. Stabilization mechanisms, Atmos. Chem. Phys., 3, 1093-1100, 2003, http://www.atmos-chem-phys.net/3/1093/2003/.

Marti, J. and Mauersberger, K.: A survey and new measurements of ice vapor pressure at temperatures between 170 and $250 \mathrm{~K}$, Geophys. Res. Lett., 20, 363-366, 1993.

Meier, A. and Hendricks, J.: Model studies on the sensitivity of upper tropospheric chemistry to heterogeneous uptake of $\mathrm{HNO}_{3}$ on cirrus ice particles, J. Geophys. Res., 107, 4696, doi:10.1029/2001JD001735, 2002.

Meilinger, S. K., Kärcher, B., von Kuhlmann, R., and Peter, Th.: On the impact of heterogeneous chemistry on ozone in the tropopause region, Geophys. Res. Lett., 28, 515-518, 2001.

Mitev V., Matthey, R., and Makarov, V.: Miniature backscatter lidar for cloud and aerosol observation from high altitude aircraft, Recent Res. Devel. Geophys., 4, 207-223, ISBN:81-7736-076-0, Research Signpost, 2002.

Peter, Th., Luo, B. P., Wirth, M., Kiemle, C., Flentje, H., Yushkov, V. A., Khattatov, V., Rudakov, V., Thomas, A., Borrmann, S., Toci, G., Mazzinghi, P., Beuermann, J., Schiller, C., Cairo, F., Di Donfrancesco, G., Adriani, A., Volk, C. M., Ström, J., Noone, K., Mitev, V., MacKenzie, R. A., Carslaw, K. S., Trautmann, T., Santacesaria, V., and Stefanutti, L.: Ultrathin tropical tropopause clouds (UTTCs): I. Cloud morphology and occurrence, Atmos. Chem. Phys., 3, 1083-1091, 2003, http://www.atmos-chem-phys.net/3/1083/2003/.

Popp, P. J., Gao, R. S., Marcy, T. P., Fahey, D. W., Hudson, P. K., Thompson, T. L., Kärcher, B., Ridley, B. A., Weinheimer, A. J., Knapp, D. J., Montzka, D. D., Baumgardner, D. G., Garrett, T. J., Weinstock, E. M., Smith, J. B., Sayres, D. S., Pittman, J. V., Dhaniyala, S., Bui, T. P., and Mahoney, M. J.: Nitric acid uptake on subtropical cirrus cloud particles, J. Geophys. Res., 109, D06302, doi:10.1029/2003JD004255, 2004.

Popp, P. J., Marcy, T. P., Jensen, E. J., Kärcher, B., Fahey, D. W., Gao, R. S., Thompson, T. L., Rosenlof, K. H., Richard, E. C., Herman, R. L., Weinstock, E. M., Smith, J. B., May, R. D., Vömel, H., Wilson, J. C., Heymsfield, A. J., Mahoney, M. J., and Thompson, A. M.: The observation of nitric acid-containing particles in the tropical lower stratosphere, Atmos. Chem. Phys., 6, 601-611, 2006, http://www.atmos-chem-phys.net/6/601/2006/.

Schiller, C., A. Afchine, N. Eicke, C. Feigl, H. Fischer, A. Giez, 
P. Konopka, H. Schlager, F. Tuitjer, F. G. Wienhold, M. Zger: Ice partice formation and sedimentation in the tropopause region: A case study based on in situ measurements of total water during POLSTAR 1997, Geophys. Res. Lett., 26, 2219-2222, doi:10.1029/1999GL900337, 1999.

Wang, Z. and Sassen, K.: Cirrus cloud microphysical property retrieval using lidar and radar measurements. Part II: Midlatitude cirrus microphysical and radiative properties, J. Atmos. Sci., 59, 2291-2302, 2002.

Voigt, C., Schlager, H., Luo, B. P., Dörnbrack, A., Roiger, A., Stock, P., Curtius, J., Vössing, H., Borrmann, S., Davies, S., Konopka, P., Schiller, C., Shur, G., and Peter, Th.: Nitric Acid Trihydrate (NAT) formation at low NAT supersaturation in Arctic Polar Stratospheric Clouds, Atmos. Chem. Phys., 5, 1371-1380, 2005,

http://www.atmos-chem-phys.net/5/1371/2005/.
Voigt, C., Schlager, H., H. Ziereis, B. Kärcher, B. P. Luo, C. Schiller, M. Krämer, P. J. Popp, H. Irie, Y. Kondo: Nitric acid uptake in cirrus clouds, Geophys. Res. Lett., 33, L05803, doi:10.1029/2005GL025159, 2006.

Ziereis, H., Minikin, A., Schlager, H., Gayet, J.-F., Auriol, F., Stock, P., Baehr, J., Petzold, A., Schumann, U., Weinheimer, A., Ridley, B., and Ström, J.: Uptake of reactive nitrogen on cirrus cloud particles during INCA, Geophys. Res. Lett., 31, L05115, doi:10.1029/2003GL018794, 2004. 